

\title{
Mechanical considerations in impaction bone grafting
}

\author{
N. T. Brewster, W. J. Gillespie, C. R. Howie, S. P. G. Madabhushi, \\ A. S. Usmani, D. R. Fairbairn \\ From the University of Edinburgh and Princess Margaret Rose Orthopaedic Hospital, \\ Edinburgh, Scotland
}

$\mathbf{I}_{\mathrm{r}}^{\mathrm{n}}$ n impaction grafting of contained bone defects after revision joint arthroplasty the graft behaves as a friable aggregate and its resistance to complex forces depends on grading, normal load and compaction. Bone mills in current use produce a distribution of particle sizes more uniform than is desirable for maximising resistance to shear stresses.

We have performed experiments in vitro using morsellised allograft bone from the femoral head which have shown that its mechanical properties improve with increasing normal load and with increasing shear strains (strain hardening). The mechanical strength also increases with increasing compaction energy, and with the addition of bioglass particles to make good the deficiency in small and very small fragments. Donor femoral heads may be milled while frozen without affecting the profile of the particle size. Osteoporotic femoral heads provide a similar grading of sizes, although fewer particles are obtained from each specimen. Our findings have implications for current practice and for the future development of materials and techniques.

J Bone Joint Surg [Br] 1999;81-B:118-24.

Received 20 October 1997; Accepted after revision 20 August 1998

The outcome of revision arthroplasty of the hip is less satisfactory than that of a primary procedure for a number of reasons. After removal of a loose implant and the surrounding fibrocellular membrane, the endosteal surface

N. T. Brewster, FRCS Ed(Orth), Senior Lecturer in Orthopaedic Surgery W. J. Gillespie, FRACS Orth, Professor of Orthopaedic Surgery

C. R. Howie, FRCS Ed(Orth), Consultant Orthopaedic Surgeon

Princess Margaret Rose Orthopaedic Hospital, Fairmilehead, Edinburgh EH10 7ED, UK.

S. P. G. Madabhushi, PhD, Lecturer in Civil and Environmental Engineering

A. S. Usmani, Lecturer in Civil and Environmental Engineering

D. R. Fairbairn, $\mathrm{PhD}$, Senior Lecturer in Civil and Environmental Engineering

Department of Civil Engineering, Kings Buildings, University of Edin-

burgh, West Mains Road, Edinburgh, UK.

Correspondence should be sent to Mr C. R. Howie.

(C1999 British Editorial Society of Bone and Joint Surgery

0301-620X/99/18480 $\$ 2.00$

118 is relatively smooth and effective micro-interlock between cement and bone may not be achieved. ${ }^{1}$ Bone loss induced by wear particles may be so extensive that mechanical containment of the implant and its cement mantle is compromised.

To overcome this problem large cadaver structural acetabular and proximal femoral grafts have been used, ${ }^{2,3}$ but although areas of union between host and graft may occur, significant revascularisation of the graft usually does not. The rates of infection are high and effective restoration of function of important muscle attachments is seldom achieved.

In revision arthroplasty, bone defects have also been packed with particulate bone graft to provide both adequate initial stability and an environment in which revascularisation and incorporation of the graft into the host skeleton may occur. ${ }^{5-t}$ These objectives can sometimes be attained, ${ }^{8,9}$ although the overall rate of success and the initial conditions which allow this have not yet been fully defined.

In structural terms, compacted morsellised bone is a friable particulate aggregate, the mechanical behaviour of which should conform to established engineering theory and be testable experimentally. ${ }^{10}$ In this paper we outline the relevant theoretical considerations and report the results of an initial series of experiments designed to test their predictions in vitro.

The mechanical behaviour of particulate aggregates. The construct represented by an envelope of impacted bone around an implant but within a cylindrical shell of cortical bone is exposed to complex stress fields, which may be resolved into those normal to any possible plane of failure and those tangential to it (shear).

Resistance against shear failure is a function of two principal components, friction and interlocking. Frictional resistance does not have a constant value, but varies with the normal stress acting on the shear plane. It increases with the angle of shearing resistance of the aggregate particles, measured as the angle formed with the horizontal by the slope of an unsupported mound of particles, such as when salt or sand is poured. The angle of shearing resistance depends on the grading (the distribution of particle size) of the aggregate and to a less extent on the shape of the particles. 


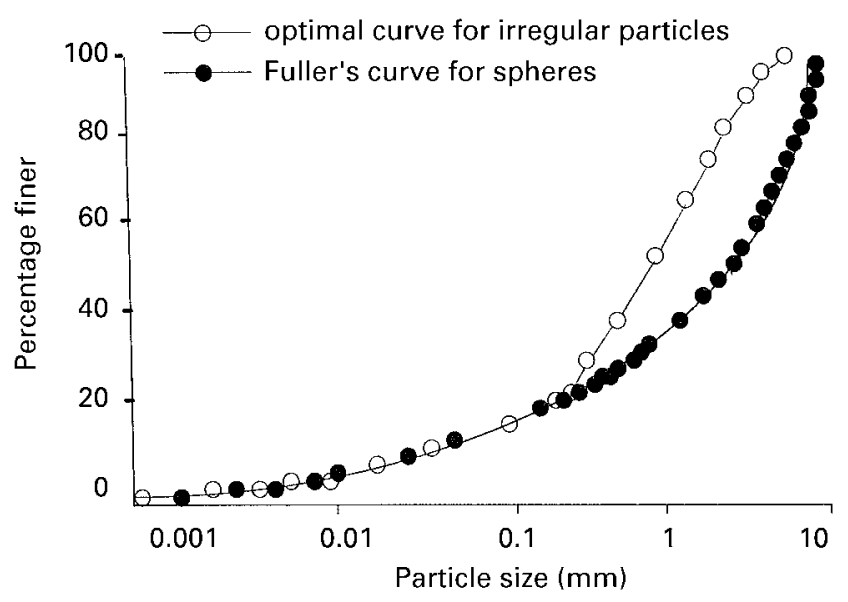

Fig. 1

The optimal distribution of particle size in a well-graded aggregate.

The second component of resistance to shear failure or shear strength, is the interlocking of particulate aggregate, which provides resistance to individual fragments riding over each other along the plane in which shear failure is occurring. Interlocking will generally be small in friable aggregates, as it is easier for them to break when they are forced to ride over each other. The broken particles form a narrow 'shear band' along the shear plane; once this is formed, the resistance to shear is determined by frictional resistance alone. The relationship between the shear strength of an aggregate $\left(\tau_{\mathrm{f}}\right)$, the interlocking (c), the normal stress applied $(\sigma)$, and the angle of shearing resistance or angle of internal friction $(\varnothing)$ is given by the MohrCoulomb equation $\left(\tau_{\mathrm{f}}=\mathrm{c}+\sigma \tan \varnothing\right)$. ${ }^{10}$

For optimum shear strength an aggregate of spherical or irregularly-shaped particles requires a mix of sizes represented by a logarithmic grading curve, (Fig. 1). For spheres, the distribution is represented by Fuller's curve, which for irregular particles is slightly modified. Aggregates with a more uniform particle size than the mechanical ideal show a steeper curve. Well-graded aggregates composed of a mixture of materials are known to have superior mechanical characteristics compared with poorly graded aggregates of one material. Thus the use of bone substitutes of appropriate particle size could, theoretically, enhance impaction grafting.

Aims. The objectives of our experiments were:

1) To determine the range and profile of particle sizes in dried-graft aggregates produced by milling allograft femoral heads using currently available bone mills, and to compare these with a theoretical predicted optimum.

2) To determine the effect of compaction on the range and profile of particle sizes.

3) To determine the effect of thawing frozen allograft on the profile of particle sizes.

4) To determine the relationship between the apparent density of osteoporotic and osteoarthritic allograft femoral heads and the range and profile of particle sizes produced.
5) To determine the preliminary stress-strain behaviour under shear of dried aggregates from osteoporotic and osteoarthritic femoral heads, of a particulate bioactive glass (Giltech Ltd, Ayr, UK), and of well-graded mixtures of dried graft and bioglass, at increasing multiples of compaction energy.

\section{Materials and Methods}

Particle size determination. We calculated the distribution of fragment sizes of morsellised bone for four commercially available bone mills used in clinical practice in the UK. Before milling, cores of bone measuring approximately $8 \times 10 \mathrm{~mm}$ were trephined along the polar axis from the centre of human femoral heads which had been donated with the patients' consent, frozen, stored at $-70^{\circ} \mathrm{C}$, and thawed before the experiment. After morsellisation, the bone was placed in $4 \%$ formal saline to remove any biohazard, washed sequentially in alcohol, acetone, alcohol and water, and dried.

The size of the fragments was calculated using sieve analysis to British Standard 1377. Ten calibrated sieves of pore diameter in a range of 10 to $0.5 \mathrm{~mm}$ were assembled in order of decreasing pore diameter with the largest at the top (Fig. 2). The morsellised bone was weighed, placed in the top sieve and the assembly shaken until no further passage of fragments down the gradient occurred. We measured the mass of particles remaining in each sieve, allowing calculation of the percentage of the graft in each

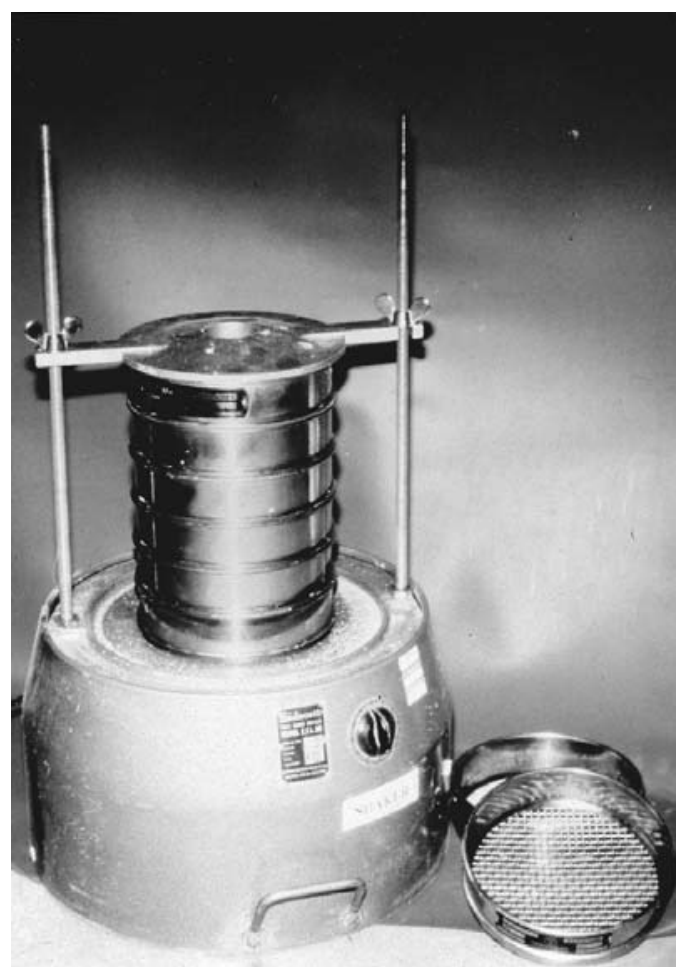

Fig. 2

The equipment for sieve analysis. 


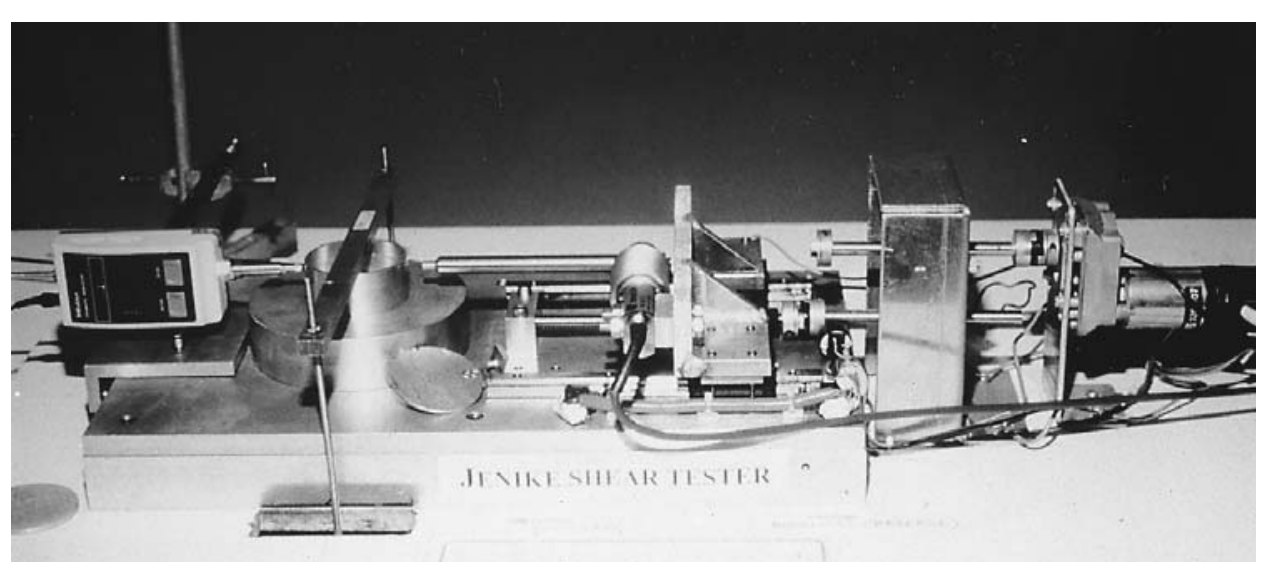

Fig. 3

The modified Jenike shear box.

sieve. Specimens were sieved on three occasions to show repeatability of the measurement. Five specimens were prepared in mill A (Aesculap), six in mill B (Norfolk and Norwich), five in mill C (Spearings), and three in mill D (Synthes). From these measurements we calculated the mean particle size (based on the mass distribution of particles in the sieves) and the coefficient of uniformity of the specimen $\left(\mathrm{C}_{\mathrm{u}}\right)$ (which is the ratio of the sieve diameter that $60 \%$ of particles will pass to that through which $10 \%$ will pass). A well-graded specimen should have a $\mathrm{C}_{\mathrm{u}}>5$. The distribution of particle size and the mean particle size for each mill were calculated and compared using the Mann-Whitney U test with 95\% confidence intervals (CI).

We formed a bone bioglass mixture so that the distribution of particle size of the specimen could be adjusted to the theoretical optimum by the addition of measured quantities of bioglass particles of appropriate sizes.

The effect of simulated femoral impaction grafting on particle size. Four femoral heads ground in one bone mill (mill B) were individually impacted into a plastic femur using the standard technique developed in Exeter ${ }^{6}$ and instruments manufactured by Howmedica International (London, UK). The impacted bone specimens were removed, processed and dried as previously described and sieve analysis was carried out. The distribution of particle size and the mean particle size for the impacted bone were compared with those of six specimens of unimpacted bone prepared from the same bone mill using the Mann-Whitney U test with $95 \%$ CI.

The influence of thawing on particle size. Four specimens were ground in one bone mill (mill B) while still frozen, the distribution of particle size and the mean particle size were calculated as indicated above, and the results were compared with six specimens prepared from the same mill using thawed bone.

Determination of apparent density. Cores of bone measuring approximately $8 \times 10 \mathrm{~mm}$ trephined from the centre of the femoral heads across the polar axis were processed as described above for morsellised bone. These were cen- trifuged until dry, then weighed and their exact dimensions measured using a vernier gauge. The apparent density was calculated as $\mathrm{g} / \mathrm{cm}^{3}$. This measurement correlates well with porosity. ${ }^{11}$ The values for apparent density for seven bone samples were compared with the particle size and distribution from one bone mill, using regression analysis with 95\% CI. Those for five bone samples prepared in one bone mill were also compared with the mechanical properties of the morsellised graft (Mohr-Coulomb yield criteria), using regression analysis with 95\% CI.

Preliminary stress/strain behaviour. Specimens of morsellised bone, of bioglass, and of well-graded bone-bioglass mixture, of known apparent density, particle size distribution and mean particle size were placed in a shear box ${ }^{10}$ (Fig. 3). This was a Jenike shear apparatus modified by the use of a circular test box to neutralise the effect of corner stresses. It consists of a cylindrical box which is split horizontally. The morsellised specimen is placed in the box and is sheared by moving the upper section of the box at a constant rate of strain. This can be performed with varying normal (compressive) loads on the specimen and the force required to produce the strain is measured.

Once placed in the box, specimens were sheared at a uniform strain of $3 \mathrm{~mm} / \mathrm{min}$ with an applied normal load varying from $17.6 \mathrm{kPa}$ to $141.57 \mathrm{kPa}$ and a stress-strain curve for each load was plotted. The shear stress at a maximum strain value $(9.5 \%)$ was plotted against the normal stress giving a straight line defined by the MohrCoulomb equation. This allowed the calculation of the Mohr-Coulomb yield criteria, the angle of shearing resistance between the particles $(\varnothing)$ and the interlocking between the particles (c). The product of two or three femoral heads was combined to provide sufficient material for shear testing. One representative sample from each bone mill was tested to allow a direct comparison of the mechanical properties for bone prepared in each of the four bone mills.

A compaction chamber was manufactured to allow compaction of specimens into a cylindrical shape which could 


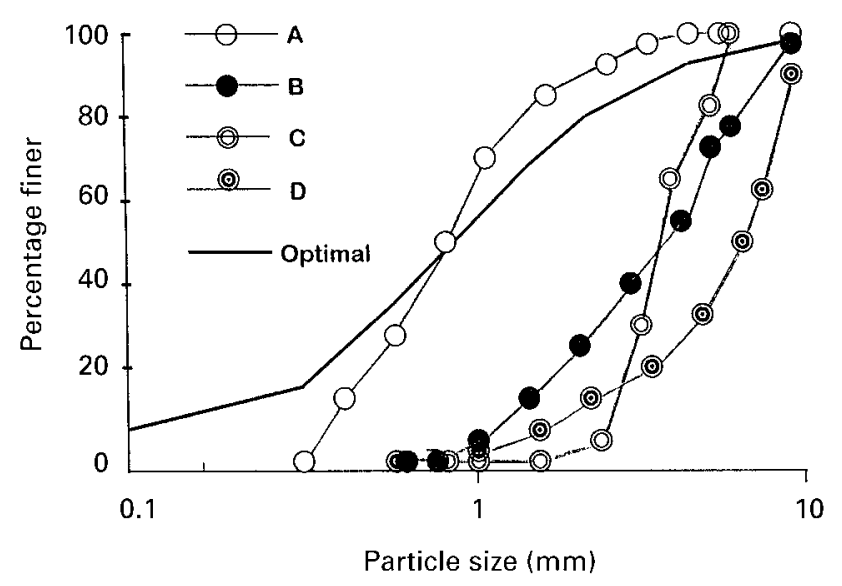

Fig. 4

Percentage mass distribution of particles for different bone mills (A to D) (representative specimen for each mill).

be directly transferred to the shear box for testing. Using a force plate to measure the force imparted per blow of the slap hammer during impaction grafting of a plastic femur, an estimate of the energy transmitted in femoral impaction grafting was calculated. One specimen each of bone, bioglass, and the bone-bioglass mixture was compacted at multiples of the energy equivalent of femoral impaction grafting from 0.5 to 2.0. Shear stress-strain measurements were then taken at a constant normal load $(95 \mathrm{kPa})$.

\section{Results}

Particle sizes in dried graft aggregates. The four bone mills tested produced a more uniform distribution of particle size than the theoretical ideal (Fig. 4). The deficiency was mainly in small and very small particles. One bone mill (C) produced a significantly more uniform particle size than the other three (A,B,D) (Tables I and II). There was no significant difference in the distribution of particle sizes between mills A, B and D (Tables I and II).

Effect of compaction on particle size profile. There was no significant difference in the $\mathrm{C}_{\mathrm{u}}(\mathrm{p}=0.59$, CI -1.12 to $1.28)$ and the mean particle size ( $p=0.45$, CI -0.4 to 1.7$)$ between impacted and unimpacted specimens.

Effect of thawing on particle size profile. There was no significant difference in the $\mathrm{C}_{\mathrm{u}}(\mathrm{p}=0.34, \mathrm{CI}-1.44$ to 0.75$)$ and mean particle size ( $p=0.33$, CI -0.3 to 1.8$)$ in milled bone which had been either frozen or thawed.

Association of apparent density of donor femoral head and particle size profile. There was no correlation between the apparent density of the femoral head and the $\mathrm{C}_{\mathrm{u}}$ (regression coefficient $-0.05, \mathrm{CI}=-0.31$ to 0.21 ) or mean size (regression coefficient $0.11, \mathrm{CI}-0.30$ to 0.52 ) of the morsellised bone fragments (Fig. 5).

Stress-strain behaviour of dried graft aggregates under shear. Morsellised bone showed strain hardening. With increasing shear strain, the peak shear stress increased (Fig.
Table I. Particle-size distribution $\left(\mathrm{C}_{\mathrm{u}}\right)$ for four bone mills

\begin{tabular}{lll}
\hline Bone mill & Median & Range \\
\hline A & 2.87 & 2.27 to 3.13 \\
B & 3.11 & 2.16 to 4.48 \\
C & 2.07 & 1.76 to 2.33 \\
D & 4.57 & 3.05 to 4.57 \\
\hline
\end{tabular}

Table II. Comparison of particle-size distribution $\left(\mathrm{C}_{\mathrm{u}}\right)$ produced by different bone mills

\begin{tabular}{lcc}
\hline Bone mills & p value & 95\% CI \\
\hline A+C & 0.02 & 0.2 to 1.4 \\
B + C & 0.01 & 0.1 to 2.4 \\
D+C & 0.04 & 0.7 to 2.8 \\
A+B & $>0.05$ & -0.8 to 1.4 \\
A+D & $>0.05$ & -0.2 to 2.3 \\
B+D & $>0.05$ & -2.4 to 1.4 \\
\hline
\end{tabular}

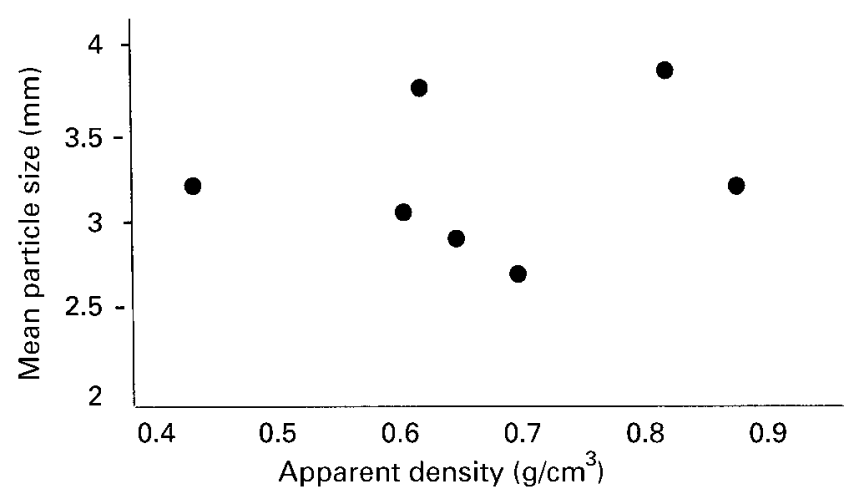

Fig. 5

Correlation between apparent density of allograft femoral head and mean particle size produced by morsellisation.

6). Increased normal load also increased the shear strength (Fig. 5). Compaction up to twice the 'standard' compaction energy increased the shear strength measured as the shear stress at $9.5 \%$ strain (Fig. 6).

There was no correlation between the apparent density of the femoral heads and the mechanical properties (MohrCoulomb yield criteria) of the morsellised bone (Table III).

The mechanical strength was greater in specimens with grading curves closer to the ideal. Uncompacted bioglass alone, even when optimally graded, had poor shear-strength characteristics compared with morsellised bone. There was no cohesive force, and the angles of internal friction and shear stress at $9.5 \%$ strain were lower than those for morsellised bone (Table IV). After compaction, bioglass remained weaker than morsellised bone from femoral heads although the proportional reduction fell with increasing compactive effort (Fig. 7).

The addition of bioglass particles to the product of a bone mill to produce an optimally graded aggregate 


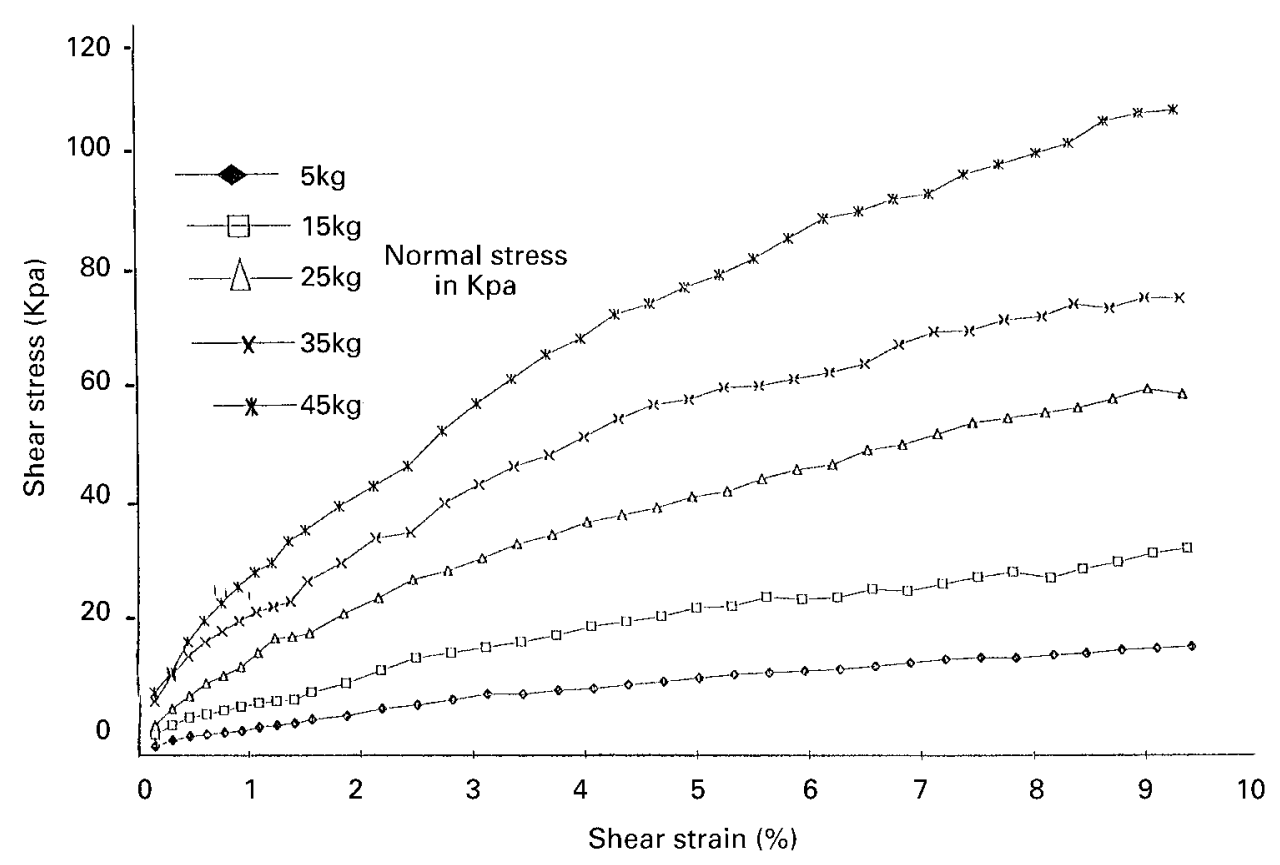

Fig. 6

Stress-strain curves for morsellised bone at different normal loads.

increased the stress at $9.5 \%$ strain once the specimen had been compacted (Table IV and Fig. 8).

\section{Discussion}

We have shown that the mechanical performance of morsellised bone derived from frozen whole femoral heads and impacted into a contained cavity is improved by the provision of a profile of particle size which approaches the theoretical optimum predicted from particulate aggregate theory. None of the bone mills tested produced an ideal profile, but the mechanical strength of well-graded morsellised bone was greater than that of a more uniform size. Shear strength is improved by adding measured quantities of small and very small fragments; in our experiments these were of a bioactive glass which alone has poorer mechanical characteristics than morsellised bone. Our findings confirm the predictions of the particulate aggregate theory, and have implications for both contemporary practice in revision joint replacement and for further research.

Implications for practice. Bone may be morsellised while still frozen without detriment to the size profile obtained. Osteoporotic bone from femoral heads obtained during

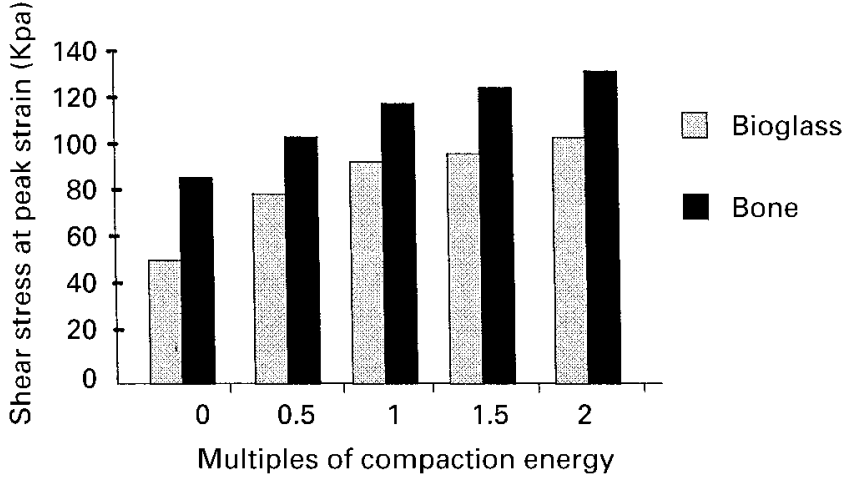

Fig. 7

Effect of compaction on the shear stress at maximum strain for morsellised bone and for bioglass.

Table III. Relationship of apparent density of femoral head to Mohr Colomb yield criteria of five specimens of morsellised bone

\begin{tabular}{lcc}
\hline $\begin{array}{l}\text { Mohr Colomb } \\
\text { yield criteria }\end{array}$ & $\begin{array}{l}\text { Regression } \\
\text { coefficient }\end{array}$ & $\mathbf{9 5 \%}$ CI \\
\hline Angle of internal friction $(\varnothing)$ & 0.02 & 0.09 to 0.13 \\
Cohesion (c) & -0.04 & -0.16 to +0.08 \\
\hline
\end{tabular}

Table IV. Shear strength parameters of morsellised bone and bioglass (modified Jenike shear apparatus)

\begin{tabular}{llll}
\hline Specimen & $\begin{array}{l}\text { Cohesion } \\
(\mathbf{c})(\mathbf{k P A})\end{array}$ & $\begin{array}{l}\text { Angle of internal } \\
\text { friction }(\boldsymbol{\emptyset})\end{array}$ & $\begin{array}{l}\text { Stress at maximum strain } \\
\text { (95kPA normal stress: } \\
\text { compactive effort 1.0) }\end{array}$ \\
\hline Morsellised bone & 5.95 & 37.81 & 120.36 \\
Well-graded bioglass & 0.0 & 27.82 & 96.67 \\
Morsellised bone/bioglass mixture & 5.45 & 36.78 & 129.21 \\
\hline
\end{tabular}




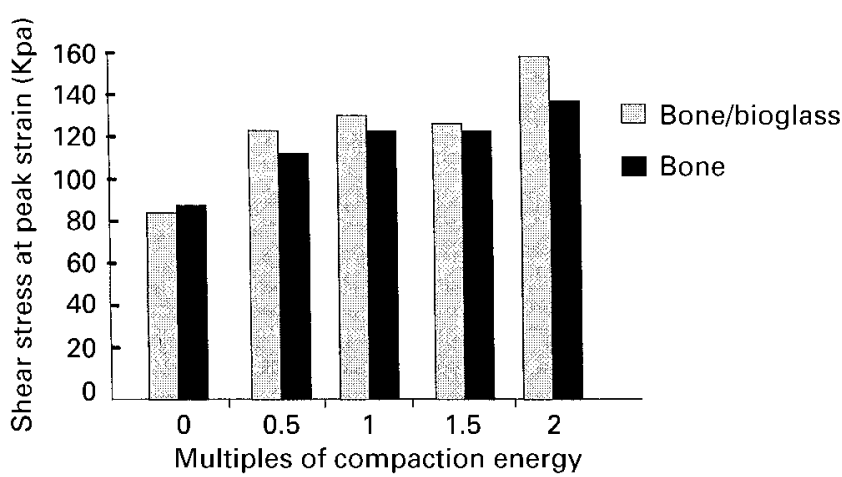

Fig. 8

Effect of compaction on the shear stress at maximum strain for morsellised bone and for well-graded bone-bioglass mix.

arthroplasty for fracture of the neck of the femur may be used since the graft size profile or the mechanical strength of the morsellised graft is not significantly different from that of osteoarthritic heads. Some tissue banks have excluded osteoporotic donors because of the difficulties of obtaining informed consent from elderly patients with hip fractures and of adverse user opinion on the quality of the bone. Less bone and more fatty and cellular marrow are obtained from each head if osteoporosis is significant, but the profile of the bone for impaction grafting is satisfactory, provided that a bone mill which will produce an appropriate size of fragment is used and the excess fluid and fat are removed.

The absolute particle size is less important than the grading. The initial mechanical stability of a prosthetic component implanted into a contained defect which has been augmented with morsellised bone graft will be greatest when the graft has a well-graded particle-size profile and has been effectively compacted. Since the aggregate is stronger with loading, it may be beneficial to allow early weight-bearing except when the construct requires extensive augmentation with screws, mesh or plates.

Implications for research. Our experiments on stressstrain behaviour, although they yielded preliminary stressstrain curves, were by no means exhaustive. Further research will involve both the Jenike shear apparatus and computer-controlled stress paths in a triaxial test apparatus, and will examine graft in its natural state. In these initial experiments we have tested dry materials, a situation different from that in vivo in which extracellular fluid, cellular debris, and proteins are also present even if compaction is extremely efficient. This is analogous to the situation in civil engineering in which, provided that adequate compaction has been achieved and is maintained, the presence of small quantities of residual water are not detrimental to, and indeed may enhance, the mechanical performance of aggregate structures. The presence of protein and peptide materials may be expected to improve cohesion. Despite these predictions we think that it is important to repeat our experiments with closer simulation of clinical conditions.
Although Slooff et $\mathrm{al}^{5}$ have reported the use of cancellous graft alone, it is our practice and that of Gie et al ${ }^{6}$ who have led the introduction of impaction grafting in the UK, to use morsellised whole femoral heads as allograft. This material contains some cortical bone and, indeed, many of the larger fragments consist partly of lamellar bone. Although contributing to initial mechanical stability, the incorporation of these fragments may be problematical.

The objective of impaction grafting is to restore living bone around the implant without loss of stability. The dynamics of the relationship between initial stability and ultimate reincorporation of the graft into the host skeleton are poorly understood. In a well-compacted, well-graded, allograft aggregate, revascularisation and reincorporation may be inhibited by the close packing of the graft. Stability may be lost as the graft is degraded in the bone remodelling cycle. It is also unclear how important incorporation of the graft is, provided that the construct remains stable over a long period and does not itself increase the formation of particulate debris to stimulate macrophage activity and further skeletal resorption.

These questions may be addressed in a number of ways. Careful observational studies of impaction grafting in human practice should be performed using outcome measures which may include radiostereometry and survivorship analysis. Randomised clinical trials are appropriate to compare directly methods in revision arthroplasty which use impaction grafting with those which do not, and to test the clinical value of additives to allograft, either to obtain optimal grading or to enhance reincorporation using bone morphogenic proteins. We think that while animal studies do not ideally replicate either the mechanical conditions in human total hip replacement or the biology of the incorporation of compacted graft, they are necessary in view of the limitations of contemporary imaging of the microcirculation and bone turnover in vivo. Finally, further investigation by experimental and numerical modelling of the mechanical conditions after impaction grafting would be valuable.

Impaction grafting has proved to be a promising technique. Since, however, there are hazards and major costs attached to its use, it is important to learn more about both its mechanical and biological dimensions, and its long-term outcome, if it is to fulfil this promise.

We gratefully acknowledge the technical assistance of Stuart Robertson, Euan Kerr and Chris Davidson. We thank Professor Gordon Murray for his advice and assistance with statistical analysis. Giltech plc supplied the bioglass in particulate form. Howmedica International provided a grant for experimental expenses.

Although none of the authors have received or will receive benefits for personal or professional use from a commercial party related directly or indirectly to the subject of this article, benefits have been or will be received but are directed solely to a research fund, foundation, educational institution, or other non-profit institution with which one or more of the authors is ssociated.

\section{References}

1. Dohmae Y, Bechtold JE, Sherman RE, Puno RM, Gustilo RB. Reduction in cement-bone interface shear strength between primary and revision arthroplasty. Clin Orthop 1988;236:214-20. 
2. Gross AE, Hutchinson CR, Alexeeff M, et al. Proximal femoral allografts for reconstruction of bone stock in revision arthroplasty of the hip. Clin Orthop 1995;319:151-8.

3. Shinar AA, Harris WH. Bulk structural autogenous grafts and allografts for reconstruction of the acetabulum in total hip arthroplasty. J Bone Joint Surg [Am] 1997;79-A:159-68.

4. Hooten JP, Engh CA, Heekin RD, Vinh TN. Structural bulk allografts in acetabular reconstruction: analysis of two grafts retrieved at post-mortem. J Bone Joint Surg [Br] 1996;78-B:270-5.

5. Slooff TJJH, Buma P, Schreurs BW, et al. Acetabular and femoral reconstruction with impacted graft and cement. Clin Orthop 1996;324: 108-15.

6. Gie GA, Linder L, Ling RSM, Timperley AJ. Contained morsellized allograft in revision total hip arthroplasty: a minimum five year follow up. J Bone Joint Surg [Br] 1996;78-B:Supp 1:71.
7. Malkani AL, Voor MJ, Fee KA, Bates CS. Femoral component revision using impacted morsellised cancellous graft: a biomechanical study of implant stability. J Bone Joint Surg [Br] 1996;78-B:973-8.

8. Buma P, Lamerigts N, Schreurs BW, et al. Impacted graft incorporation after cemented acetabular revision: histological evaluation in 8 patients. Acta Orthop Scand 1996;67:536-40.

9. Berzins A, Sumner DR, Wasielewski RC, Galante JO. Impacted particulate allograft for femoral revision total hip arthroplasty: in vitro mechanical stability and effects of cement pressurization. J Arthroplasty 1996;11:500-6.

10. Craig RF. Soil mechanics. 5th Edition. London: Chapman and Hall, 1993.

11. Lindahl O, Lindgren A. Grading of osteoporosis in autopsy specimens. Acta Orthop Scand 1962;32:85-100. 